Rev. Elet. em Gestão, Educação e Tecnologia Ambiental (e-ISSN: 2236-1170)

\title{
CITRICULTURA E AGRONEGÓCIO COOPERATIVO NO BRASIL
}

\author{
CITRICULTURA AND COOPERATIVE AGRIBUSINESS IN BRAZIL
}

\author{
Aline Zulian'1, Andréa Cristina Dörr², Sabrina Cantarelli Almeida ${ }^{3}$ \\ ${ }^{1}$ Universidade Federal de Santa Maria (UFSM) - Mestranda do Programa de Pós-Graduação em Economia e \\ Desenvolvimento. E-mail: alinezulian@hotmail.com \\ ${ }^{2}$ UFSM - Profa Dra Adjunta do Departamento de Ciências Econômicas. E-mail:andreadoerr@yahoo.com.br \\ ${ }^{3}$ UFSM - Mestranda do Programa de Pós-Graduação em Economia e Desenvolvimento. E-mail: binalmeida@ig.com.br
}

http://dx.doi.org/10.5902/223611708700

\section{RESUMO}

A cadeia citrícola vem ganhando espaço no agronegócio brasileiro com a ampliação do mercado e o aprimoramento da atividade. O Brasil é destaque na produção de laranjas e na exportação do suco da fruta. Tendo em vista que a citricultura, assim como outras atividades agropecuárias, envolve o processamento das frutas, essa atividade exige maiores investimentos e a agroindustrialização. Assim, o sistema agroindustrial citrícola engloba muitos procedimentos, sendo que as cooperativas e associações representam formas de organizações econômicas que muitas vezes possibilitam o desenvolvimento de pequenos produtores rurais e proporcionam formas de inserir-se no mercado competitivo. Este estudo busca fazer um panorama da citricultura, com foco na laranja e tangerina, além de descrever a importância do agronegócio cooperativo. Desse modo, conclui-se que o setor citrícola tem grande importância para o agronegócio brasileiro e que a presença de uma cooperativa pode ser um elemento favorável ao crescimento de pequenos produtores.

Palavras-chave: cadeia citrícola, cooperativa, sistema agroindustrial

\begin{abstract}
The citrus chain has gained importance in Brazilian agribusiness with market expansion and improvement activity. Brazil is highlighted in orange production and export of fruit juice. Considering that the citrus industry as well as other agricultural activities, involves processing of fruits, this activity requires greater investment and industrialization. Thus, the system of citrus agribusiness encompasses many procedures, and cooperatives and associations are forms of economic organizations that often enable the development of small farmers and provide ways to insert themselves in the competitive market. This study seeks to make a panorama of citrus, with a focus on orange and tangerine, and describe the importance of agribusiness cooperative. Thus, we conclude that the citrus sector has great importance for the Brazilian agribusiness and the presence of a cooperative may be a favorable factor for the growth of small producers.
\end{abstract}

Keywords: citrus chain, cooperative, agribusiness system 


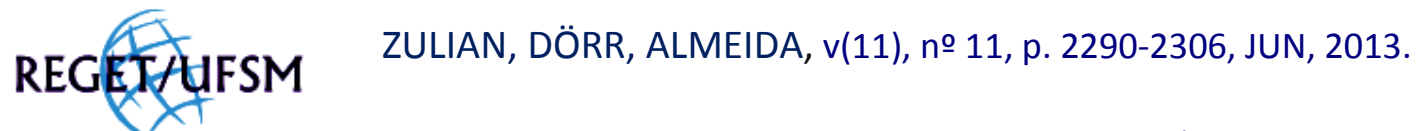

Rev. Elet. em Gestão, Educação e Tecnologia Ambiental (e-ISSN: 2236-1170)

\section{INTRODUÇÃO}

A cadeia citrícola vem ganhando espaço no agronegócio brasileiro com a ampliação do mercado e o aprimoramento da atividade. O Brasil possui mudas e viveiros certificados, cultivo de frutas cítricas, produção do suco e canais de distribuição internacional que levam os produtos ao consumidor europeu, norte-americano e asiático (NEVES et al., 2010, p. 06).

Além de ser o maior produtor mundial de laranjas, o Brasil também é o maior exportador do suco de laranja, atendendo a diversos países. Segundo Neves et al. (2010, p. 08), em 2009, as exportações do complexo citros somaram de 2,9 milhões de toneladas, sendo que o Brasil é responsável por $50 \%$ da produção mundial de suco de laranja, e $98 \%$ do que ele produz é exportado. Ou seja, de cada cinco copos de suco de laranja consumidos no mundo, três são produzidos nas fábricas brasileiras e, além disso, o suco de laranja é a bebida de frutas mais consumida no mundo, com 35\% de participação entre os sucos (NEVES et al., 2010, p. 08).

Com o resultado desse sucesso na produção citrícola, de acordo com Neves et al. (2010), o PIB do setor foi de US\$ 6,5 bilhões em 2009, sendo US\$ 4,39 bilhões do mercado interno e US\$ 2,15 bilhões do mercado externo. Cabe destacar que outro setor que está ganhando destaque mundial dentro do sistema agroindustrial citrícola é o mercado de óleos essenciais cítricos. 0 Brasil encontra-se entre os principais países fornecedores dos óleos essenciais, ao lado da Índia, China e Indonésia, que são considerados os quatro grandes produtores mundiais (BIZZO et al., 2009, p. 588). Segundo dados do Ministério do Desenvolvimento, Indústria e Comércio Exterior (ALICEWEB, 2012), o Brasil apresentou, no ano de 2011, um volume total exportado de mais de 24 milhões de quilogramas de óleo essencial (valor maior que US\$128 milhões).

Contudo, para ter sucesso na produção agrícola, principalmente no caso de pequenos produtores, são necessárias medidas que envolvam mudanças na organização e preocupação com a diferenciação da produção no mercado. A concorrência no mercado nacional e internacional tem levado a importantes mudanças nos negócios agropecuários, que buscam maior eficiência em relação à necessidade de tornar mais competitivos seus produtos (MILOCA et al., 2005). De modo geral, o agronegócio tem se tornado mais dinâmico e vêm buscando maior coordenação entre os agentes, exigindo maior organização e acesso a novos mercados, representando um desafio ao pequeno produtor.

A cooperativa agropecuária pode apresentar-se como uma forma de possibilitar a eficiência econômica de pequenos produtores e a concorrência com grandes empresas do mercado. Ferreira (2009) afirma que o sistema cooperativo funciona como uma solução para os pequenos e médios produtores. De acordo com o mesmo autor, esse sistema é baseado na autogestão, e faz com que as cooperativas adotem estratégias de gestão adequadas e eficientes.

A importância da citricultura vai além da geração de divisas para a economia brasileira. Este setor tem grandes impactos na criação de empregos, na formação de capital, na geração de renda, na agregação de valor e, também, no desenvolvimento regional. Conforme Neves et al. (2010, p. 08), esse setor promoveu um total de 230 mil empregos diretos e indiretos no Brasil e uma massa salarial anual de $\mathrm{R} \$ 676$ milhões.

Tendo em vista a importância da citricultura para o Brasil, o objetivo geral deste estudo consiste em fazer um panorama da citricultura no país, com foco na laranja e na tangerina, e analisar o papel do agronegócio cooperativo. Para a descrição do panorama geral da citricultura e caracterização da atividade, desenvolveu-se uma pesquisa bibliográfica com dados secundários. 
REGEIATFSM ZULIAN, DÖRR, ALMEIDA, v(11), no 11, p. 2290-2306, JUN, 2013.

Rev. Elet. em Gestão, Educação e Tecnologia Ambiental (e-ISSN: 2236-1170)

\section{CITRICULTURA: CARACTERÍSTICAS E EVOLUÇÃO HISTÓRICA}

A citricultura é uma importante atividade do agronegócio brasileiro. As frutas que pertencem a este grupo são do gênero Citrus, sendo que as principais espécies são: as laranjas doces, as tangerinas, os limões, as limas ácidas, os pomelos, e outras espécies consideradas menos conhecidas (DONADIO et al., 1998, p. 01). Segundo a fonte acima, para as tangerinas ou mandarinas ${ }^{1}$ existem muitas variedades, sendo que são quatro as de uso comercial: as Satsumas, as Mexericas, as do grupo King e as Mandarinas ou Tangerinas comuns. Conforme Donadio et al. (1998, p. 02), provavelmente, as mandarinas tiveram origem no nordeste da Índia e no sul da China, embora as outras espécies citadas possam ter origem em outros lugares.

As primeiras plantas cítricas foram introduzidas no Brasil pelos portugueses, que trouxeram as mudas da Espanha, logo no início da colonização (NEVES e JANK, 2006, p. 07). 0 objetivo em trazer essas frutas era para criar um abastecimento de vitamina $C$ para ser utilizada como antídoto do escorbuto, doença que matava a maior parte das tripulações na época (NEVES e JANK, 2006, p. 07). Essas mudas apresentaram adaptação climática, fazendo com que elas se espalhassem para todo o território brasileiro. Mas, desde o início, foi na região centro-sul do Brasil que a citricultura teve maior destaque, principalmente em função das condições edafo-climáticas e pela proximidade com o mercado consumidor. Assim, São Paulo é reconhecido até hoje pelo domínio neste setor, sendo que das 1.178 máquinas extratoras do suco de laranja instaladas no país, 1.061 estão localizadas no estado de São Paulo, 72 estão no sul e 45 no nordeste (NEVES et al., 2010, p. 13).

A citricultura está suscetível as mudanças climáticas e as doenças que afetam as frutas. Essas situações interferem na produção, no preço de mercado e, consequentemente, em todo andamento da atividade. A consolidação da indústria brasileira no mercado de citros ocorreu definitivamente após as geadas que afetaram a Flórida nos anos de 1977, 1981, 1982, 1983, 1985 e 1989, causando perdas na produção americana de laranja e firmando as exportações de suco brasileiro (NEVES et al., 2010, p. 13). Com o passar dos anos, de acordo com o mesmo autor, como qualquer outra atividade agropecuária, houve períodos de prosperidade, que aumentou o número de produtores na atividade citrícola, mas também houve períodos de recessão, muitas vezes decorrentes desse hiato temporal entre o início do plantio, o crescimento das plantas e o amadurecimento das frutas para venda.

O suco de laranja foi, na verdade, uma opção alternativa de comercializar a fruta quando, no início da década de 1940, período da Segunda Guerra Mundial, ela foi proibida de ser exportada in natura (NEVES e JANK, 2006, p. 08). Assim, surgiram empresas processadoras e exportadoras do suco, principalmente no estado de São Paulo, que beneficiaram os produtores, as indústrias, os municípios através da agregação de valor com a transformação da laranja em suco. Ou seja, conforme Neves e Jank (2006), resultaram-se benefícios para os setores antes da porteira (fornecedores de insumos para a produção), dentro da porteira (a produção propriamente dita), e para os setores pós-fazenda (indústrias processadoras, empresas de distribuição). Além disso,

\footnotetext{
1 A tangerina é conhecida popularmente por diferentes nomes, variando conforme a região brasileira. No Rio Grande do Sul, por exemplo, ela é conhecida como bergamota, enquanto que nas regiões Centro-Oeste e Sudeste do Brasil ela leva o nome de mexerica. Neste trabalho, utilizar-se-á a palavra tangerina ao fazer-se referência as bergamotas em geral. 
REGEIUTSMLIAN, DÖRR, ALMEIDA, v(11), no 11, p. 2290-2306, JUN, 2013.

Rev. Elet. em Gestão, Educação e Tecnologia Ambiental (e-ISSN: 2236-1170)

possibilitou o desenvolvimento do setor de pesquisas científicas com avanços tecnológicos e do mercado de trabalho.

Com base em Neves et al. (2010, p. 14), em 2009/10, após uma grande queda no preço do suco de laranja em função da crise mundial de 2008, que alterou o comportamento do consumidor, em que passou a preferir produtos mais baratos, verificou-se uma melhora nos preços em função da redução da produção nas duas principais regiões citrícolas do mundo.

\section{SISTEMA AGROINDUSTRIAL CITRÍCOLA}

A maioria dos estudos bibliográficos sobre sistemas agroindustriais ou cadeias produtivas faz uso do referencial teórico da Economia dos Custos de Transação. Diferente destes, este trabalho possui ênfase apenas na delimitação do sistema agroindustrial no setor citrícola e na sua aplicação para o estudo de caso em questão, tentando, ao final, mapear os canais adotados pela cooperativa Ecocitrus.

Neves (1995) desenvolveu um trabalho sobre o sistema agroindustrial citrícola com ênfase nas teorias dos custos de transação e do agribusiness proposto por Harvard. Dentro do objetivo geral em utilizar essas duas teorias estava o problema de analisar as relações entre produtores e indústrias do setor, e verificar se a forma de coordenação desse mercado é mista e eficiente sob a ótica da economia dos custos de transação. Para isso, foram feitas entrevistas com perguntas que tratassem da agregação de valor, transações entre os segmentos, risco, frequência das transações, especificidade de ativos, oportunismo, contratos, entre outros. Os resultados apontaram a confirmação da eficiência e estabilidade da relação mista, apontando que esta forma ocorre porque existe desequilíbrio no mercado (NEVES, 1995).

Neves e Marino (2002), num trabalho sobre a competitividade de cadeias integradas no Brasil, com ênfase na citricultura, demonstram o Sistema Agroindustrial Citrícola (Figura 1). Nesta análise estão sendo contemplados os setores de pesquisa, produção de insumos, produção de frutas, industrialização, acondicionamento, distribuição até chegar ao consumidor final. 
Rev. Elet. em Gestão, Educação e Tecnologia Ambiental (e-ISSN: 2236-1170)

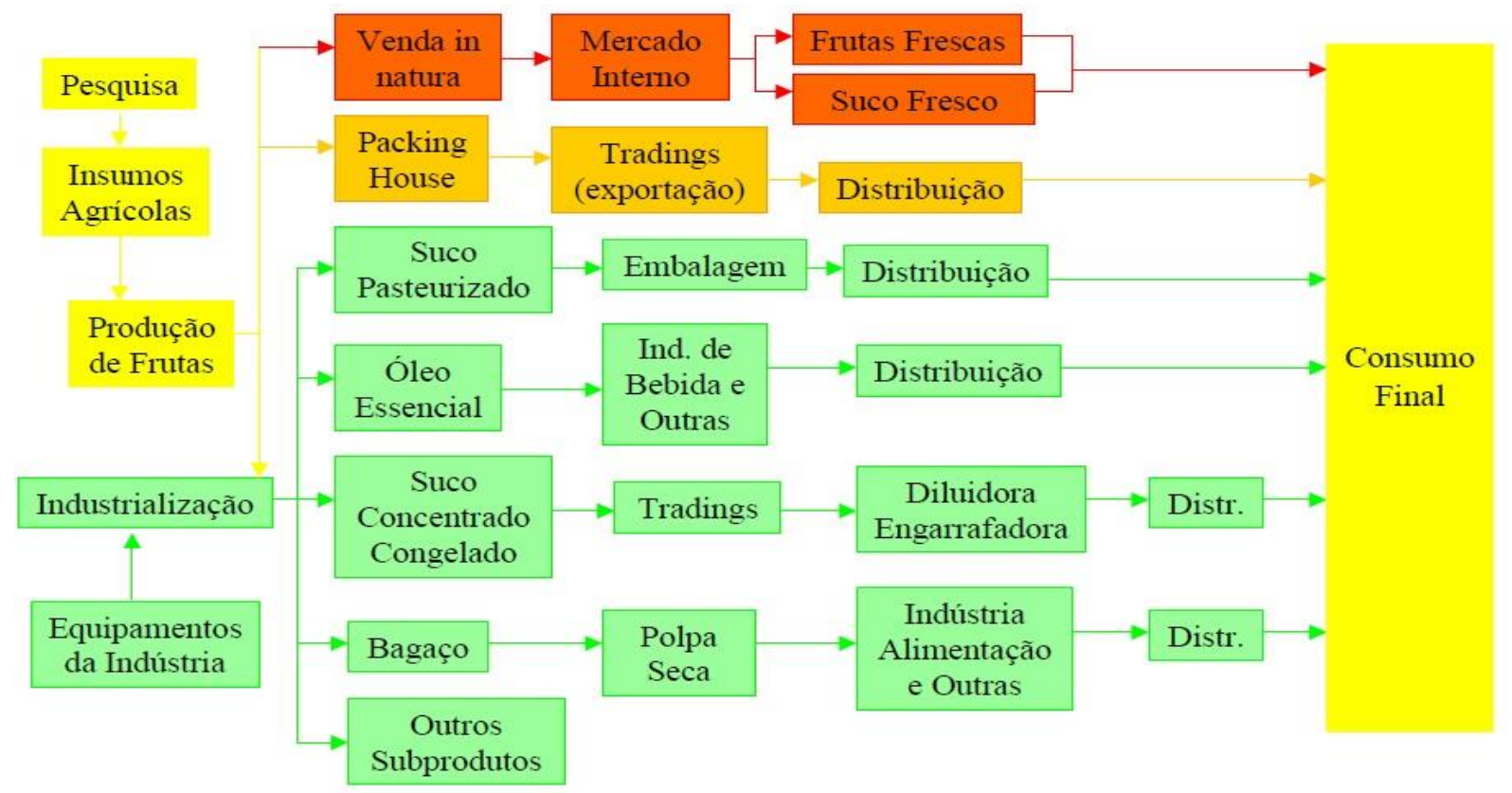

Figura 1. Sistema Agroindustrial Citrícola Fonte: Neves e Marino (2002).

\section{PANORAMA GERAL DA CITRICULTURA ${ }^{2}$}

A citricultura subdivide-se basicamente nos seguintes produtos finais: a fruta in natura ou o suco da fruta. Mas existem outros produtos derivados das frutas que estão se destacando no setor, como é o caso dos óleos essenciais.

No Brasil, em 2010, aproximadamente 165 milhões de árvores produziram frutas cítricas, enquanto que na Flórida, grande concorrente, foram 60 milhões (NEVES et al., 2010, p. 09). Segundo a mesma fonte, a densidade de árvores por hectare aumentou no Brasil, passando de 250 árvores/hectare em 1980, 357 árvores em 1990, 476 árvores em 2000 para 850 árvores por hectare em 2010. São muitos os fatores que propiciaram esse aumento, como, por exemplo, o melhoramento no cultivo de mudas.

O custo operacional de produção dos pomares da indústria é de $R \$ 7,26$ por caixa. Este custo subiu de $R \$$ 4,25/caixa em 2002/2003 para os atuais $R \$ 7,26$ (70\% a mais). Entre os custos que mais aumentaram destacam-se a mão de obra, que foi de $\mathrm{R} \$ 0,86$ por caixa para $R \$ 1,66$, e o da colheita, que foi de $R \$ 0,84$ /caixa para $R \$ 2,19 /$ caixa (160\% de aumento). Entre 1994 e 2010 o salário mínimo subiu 628\% (NEVES et al., 2010, p. 09).

Ao analisar os dados da FAOSTAT (2012), nota-se que o Brasil é o maior produtor mundial de laranja e produziu em 2010 um total de 19.112.300 toneladas, o maior volume desde 2001. Esse montante foi cultivado em 843.088 hectares de terras brasileiras, e representou $27,5 \%$ do total produzido no mundo. A produtividade da safra não apresenta grandes variações entre $2000 \mathrm{e}$

2 O foco do trabalho é análise do panorama de tangerinas e as laranjas, portanto, serão excluídas da análise geral as outras variedades de citros. 
REGEIATFSM ZULIAN, DÖRR, ALMEIDA, v(11), no 11, p. 2290-2306, JUN, 2013.

Rev. Elet. em Gestão, Educação e Tecnologia Ambiental (e-ISSN: 2236-1170)

2010, resultando, aproximadamente, em 22 laranjas por hectare. Os Estados Unidos ocupam segundo lugar, mas têm uma proporção bem menor de laranjas produzidas: 7.478.830 em 2010, que representa $10,8 \%$ da produção mundial.

De acordo com dados da FAOSTAT (2011), a maior exportadora mundial de laranjas é a Espanha que em 2009 exportou 1.430.270 toneladas da fruta, o que representa $55 \%$ da sua produção total deste ano, que foi de 2.617.700. O Brasil exportou apenas 0,15\% (ou 26.185 toneladas) do total produzido em 2009 (17.618.500 toneladas de laranja). Apesar de ser um pequeno valor de comparado ao da Espanha, o Brasil apresenta diferentes parceiros comerciais para o destino da laranja brasileira, sendo que os principais são Holanda, Arábia Saudita e a própria Espanha.

Segundo Neves et al. (2010, p. 18), o consumo interno de frutas cítricas in natura absorve parte significativa da produção brasileira, já os consumidores do mercado internacional preferem variedades de laranja de mesa produzidas nas regiões do Mediterrâneo e da Califórnia, seus principais exportadores. Um fator considerável que limita a exportação brasileira da fruta in natura são as exigências fitossanitárias. No caso de comercializar as frutas in natura para a Europa, alguns impedimentos dizem respeito à aplicação de restrições fitossanitárias para a pinta preta e cancro cítrico e a imposição de limites máximos para resíduos de pesticidas. "Os Estados Unidos proíbem as importações das frutas cítricas produzidas em qualquer parte do Brasil em função da mosca do mediterrâneo" (NEVES et al., 2010, p. 24).

Além disso, segundo Neves et al. (2010, p. 18), deve-se considerar o aumento de produção de laranja na Espanha e nos países do continente africano, reduzindo as exportações nacionais de fruta in natura. Enquanto que em 2001 as exportações brasileiras de laranja in natura somaram 139.582 toneladas da fruta (ou 3,4 milhões de caixas), o equivalente a US\$ 27,5 milhões, em 2009 foram exportadas apenas 26.185 toneladas (ou 641 mil caixas ${ }^{3}$ de laranjas), o que equivale a US\$11,3 milhões. Segundo Neves et al. (2010, p. 19), além dos itens já citados acima, essa queda expressiva no total exportado da fruta in natura ocorreu em razão da forte expansão das exportações do Suco de Laranja Não Concentrado (NFC).

Apesar disso, o montante financeiro das exportações de citros in natura (laranja, limão/lima, tangerina e pomelo) corresponde a cerca de $60 \%$ das exportações de manga ou $45 \%$ das de uva (NEVES et al., 2010, p. 19). Segundo essa mesma fonte, aumentaram os preços médios das frutas exportadas da safra 2000/01 para a de 2009/10, fazendo com que a caixa de laranja passasse de US\$ 8,00 para US\$ 18,00 neste período.

O maior importador mundial de laranja é a Alemanha, chegando a importar em 2009, 511.247 toneladas da fruta. Mesmo que o Brasil seja o maior produtor de laranja do mundo e exporte pouco, ele também importa uma pequena quantidade. O Brasil importou, em 2009, 1.824 toneladas da fruta, sendo a maior parte, 73\%, originária da Espanha. O montante importado é inferior ao montante exportado, de modo que o saldo da balança comercial para esse produto seja superavitário.

"As tangerinas diferem das laranjas, porque sua produção se destina quase que exclusivamente ao mercado de frutas frescas" (RAPPA, 2004). Assim como a da laranja, a produção brasileira de tangerinas também foi maior em 2010 se comparada ao ano anterior, atingindo um total de 1.122.730 toneladas, e permanecendo em 3이 lugar no ranking de maior produtor mundial

3 Caixas com aproximadamente $40,8 \mathrm{~kg}$ de laranjas. 


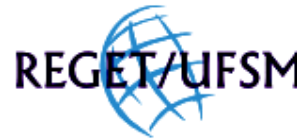

ZULIAN, DÖRR, ALMEIDA, v(11), no 11, p. 2290-2306, JUN, 2013.

Rev. Elet. em Gestão, Educação e Tecnologia Ambiental (e-ISSN: 2236-1170)

dessa fruta. Os maiores produtores de tangerina são: China, Espanha e Brasil, que representaram em 2010, aproximadamente, $61 \%$ da produção mundial de tangerinas, mandarinas e clementinas ${ }^{4}$.

O montante da fruta que é exportado mundialmente vem aumentando com o passar dos anos, sendo que o valor referente a 2009 foi igual a 4.146.265 toneladas de tangerinas. A Espanha é responsável por mais da metade da exportação mundial de tangerinas, com um total de 1.486.020 toneladas da fruta exportadas em 2009.

São vários os destinos para a tangerina brasileira. Entre os principais países que importam a fruta do Brasil estão: o Canadá, responsável por $28 \%$ das exportações, e a Indonésia, para quem o Brasil exportou cerca de $27 \%$ do total da fruta exportada. Conforme dados da FAOSTAT (2011), a quantidade de tangerina brasileira exportada no ano de 2009 foi de 4.414 toneladas $(0,1 \%$ do total mundial de tangerina exportada), representando US\$3.281.000.

Enquanto que a pauta de destino das exportações brasileiras para a tangerina é bastante variada, são dois os países de quem o Brasil importa a fruta: Uruguai e Espanha. O Brasil importou, em 2009, 916 toneladas de tangerina (65,62\% do total importado) do Uruguai, e o restante, 480 toneladas ou $34,38 \%$, foi importado da Espanha. Considerando o saldo da balança comercial apenas para a tangerina, o Brasil possui um saldo positivo de US\$2.038.000, descontando o valor importado do exportado. Ou seja, o país possui um saldo líquido positivo neste ramo.

Conforme Rappa (2004), a produção e a exportação de tangerinas possuem algumas barreiras, como o fato de as tangerinas tradicionais serem de difícil armazenagem e, principalmente, apresentarem períodos muito estreitos de maturação e colheita. Além disso, de acordo com a mesma fonte, há problemas com a deficiência de equipamentos especiais para os tratamentos pós-colheita, que elevariam a durabilidade do produto nas prateleiras e, consequentemente, agregariam valor. Estes são obstáculos que precisam ser superados para tornarem a atividade economicamente viável e mais atrativa. Uma forma de superação é o melhoramento de variedades de tangerinas. Conforme citado por Rappa (2004), um exemplo é o caso conduzido pelos pesquisadores do Centro APTA Citros Sylvio Moreira (IAC) em que, através de melhoramentos genéticos, estão surgindo novas variedades, de maturação mais precoce e mais tardia do que as tradicionais, e com melhor resistência no transporte.

\section{SUcos cítRIcos}

O consumo de frutas e sucos cítricos é tendência mundial. O Informativo Centro de Citricultura (RAPPA, 2004) aponta que, apesar do aumento do nível de consumo mundial de frutas cítricas, há diferença de hábitos da população dos países asiáticos, que preferem tangerinas, e do Ocidente, que consomem mais laranjas e sucos processados de laranja. Segundo Neves et al. (2010, p. 08), "de cada cinco copos de suco de laranja consumidos no mundo, três são produzidos nas fábricas brasileiras" e "o suco de laranja é a bebida de frutas mais consumida no mundo, com 35\% de participação entre os sucos".

Conforme a Associação Nacional dos Exportadores de Sucos Cítricos (CITRUSBR, 2011a), enquanto que para o Brasil e os Estados Unidos mais de $70 \%$ das laranjas produzidas são para a

\footnotetext{
4 Esse é o nome do grupo designado pela FAOSTAT (2012), que classifica clementinas, tangerinas e satsumas como tipos de mandarinas (bergamotas) ou, na maioria dos casos, designadas em geral como tangerinas. 


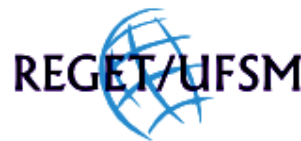

ZULIAN, DÖRR, ALMEIDA, v(11), no 11, p. 2290-2306, JUN, 2013.

Rev. Elet. em Gestão, Educação e Tecnologia Ambiental (e-ISSN: 2236-1170)

fabricação de sucos, para o México e a China, a maioria das frutas vendidas são para o consumo in natura. De acordo com a mesma fonte, "na Espanha, mais da metade das laranjas têm como destino a exportação", sendo que o principal fator que determina o destino final da fruta é o seu rendimento, que indica se elas possuem a quantidade de sólidos solúveis necessária para o uso industrial.

Devido ao caráter empreendedor da indústria de sucos, na década de 1990, surgiram as primeiras agroindústrias brasileiras nos solos estrangeiros, o que consolidou o seu poder de mercado (NEVES et al., 2010, p. 16). Considerando que na safra 2009/10 a indústria brasileira utilizou $86 \%$ de toda a laranja produzida no país, $15 \%$ destas para a produção de NFC (suco de laranja não concentrado) e $85 \%$ na produção de FCOJ (suco de laranja concentrado e congelado), pode-se verificar a importância da agroindustrialização na citricultura (CITRUSBR, 2011a).

Conforme dados da FAOSTAT (2011), o Brasil é o maior exportador do suco de laranja, destinando ao exterior, em 2009, 2.069.188 toneladas do suco (concentrado e não concentrado). Uma análise mais precisa pode ser feita ao analisar a Figura 2 e a Figura 3. Pode-se perceber que a proporção de suco não concentrado que é comercializado mundialmente vem aumentando, passando de 2.276.425 toneladas no ano 2000 para 4.459.099 toneladas em 2009. Em contrapartida, a quantidade exportada de suco concentrado se encontra bem abaixo do volume exportável de suco não concentrado e apresenta uma tendência estável e de declínio, partindo de 1.519.640 toneladas em 2000 para 944.090 toneladas de suco concentrado exportado em 2009.

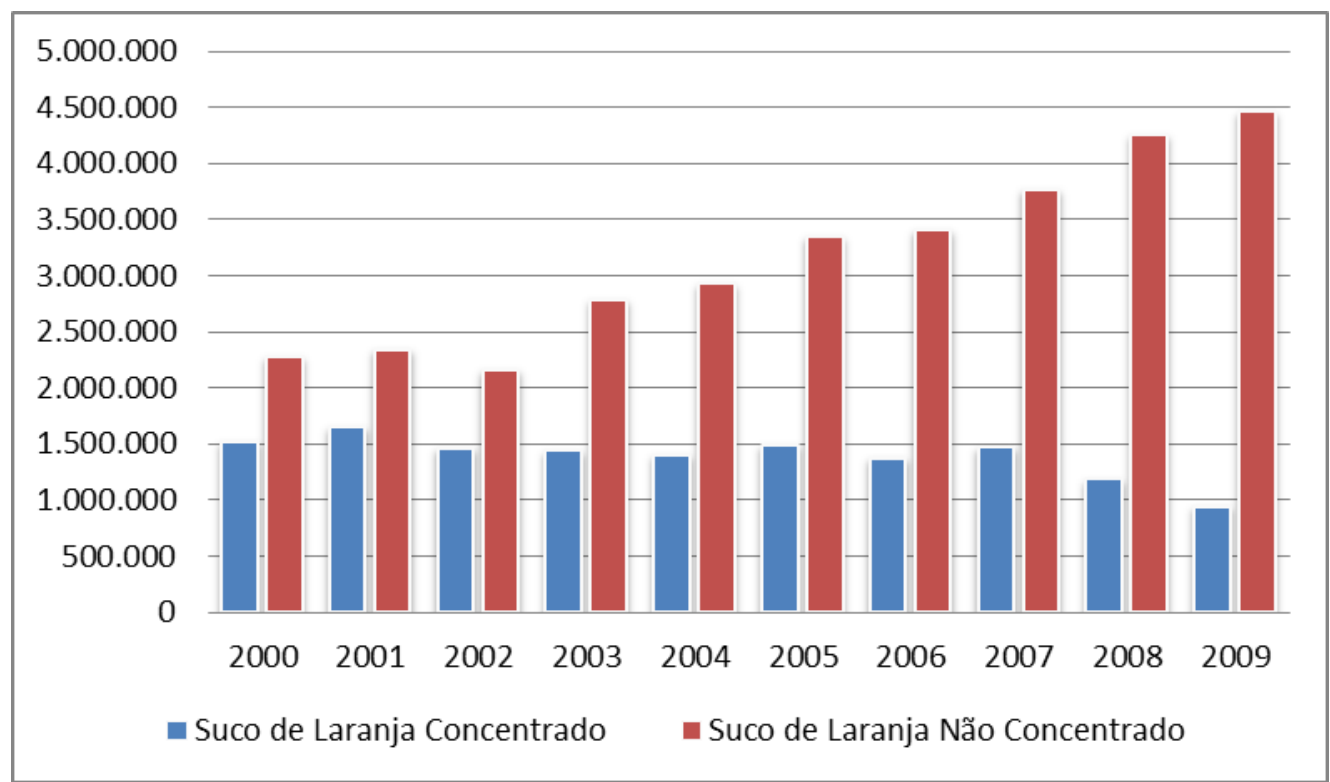

Figura 2. Quantidade (t) mundial exportada de suco de laranja concentrado e não concentrado de 2000 a 2009 Fonte: Elaborado pela autora com dados de FAOSTAT (2011).

A partir deste cenário mundial, percebe-se na Figura 3, que a situação brasileira segue as oscilações mundiais. Há uma tendência de crescimento da exportação brasileira de suco não concentrado, passando de 52.395 toneladas (US\$14.399.000) em 2000 para 1.494 .400 toneladas em 2009 (US\$913.037.000), uma quantidade quase trinta vezes maior. Enquanto que o montante 


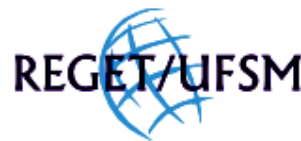

ZULIAN, DÖRR, ALMEIDA, v(11), no 11, p. 2290-2306, JUN, 2013.

Rev. Elet. em Gestão, Educação e Tecnologia Ambiental (e-ISSN: 2236-1170)

de suco concentrado exportado vem caindo gradativamente, passando de 1.224.460 toneladas (US\$ 1.019.260.000) no ano de 2000 e atingindo um total de 574.788 toneladas em 2009 (US\$ 706.131.000).

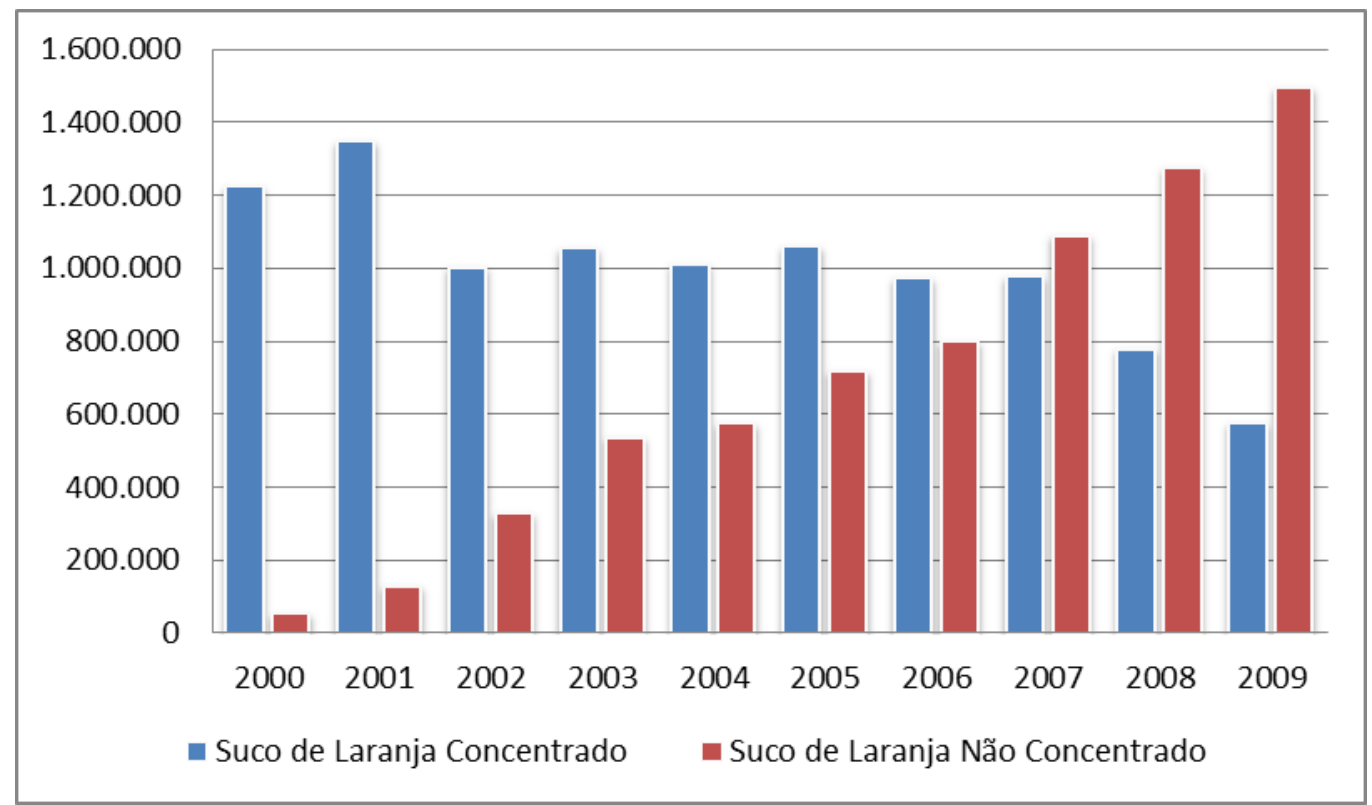

Figura 3. Quantidade (t) brasileira exportada de suco de laranja concentrado e não concentrado de 2000 a 2009 Fonte: Elaborado pela autora com dados de FAOSTAT (2011).

Dessa forma, um dos motivos para esse notável crescimento das exportações de suco não concentrado (NFC) e decréscimo da exportação do suco concentrado, é que, como grande parte do volume do NFC compõe-se da água da fruta, o seu valor em dólares e seu volume em relação ao suco concentrado são mais baixos (CITRUSBR, 2011a).

O suco de laranja brasileiro apresenta diferentes barreiras tarifárias conforme o país importador. Segundo Neves et al. (2010, p. 23), para acessar o mercado europeu, o suco brasileiro é tarifado em 12,2\%, enquanto que os sucos oriundos do Caribe, norte da África e México são isentos de tarifa. Nos Estados Unidos, conforme mesma fonte, o suco concentrado e congelado é tarifado em US\$ 415/tonelada e o NFC é tarifado em US\$ 42/tonelada. Japão, Coréia do Sul, China e Austrália são também alguns países que cobram tarifas sobre o suco de laranja do Brasil (NEVES et al., 2010, p. 23).

Com exceção dos Estados Unidos, cujo tributo é um valor fixo sobre o volume, os demais países consideram o valor financeiro de venda. Assim, quanto maior o preço do suco de laranja, maior será a tarifa alfandegária paga pelo Brasil. Essa dinâmica potencializa o efeito de subida de preço do produto na gôndola do supermercado, diminuindo a competitividade do sabor laranja em relação aos sucos de outras frutas, como a maçã, pêra, framboesa e morango, que em grande parte são produzidas nas próprias regiões onde são consumidas, sendo, portanto, isentas de barreiras tarifárias em seus mercados (NEVES et al., 2010, p. 23). 


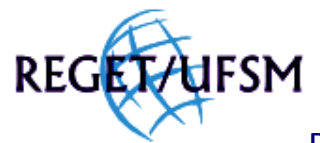

ZULIAN, DÖRR, ALMEIDA, v(11), no 11, p. 2290-2306, JUN, 2013.

Rev. Elet. em Gestão, Educação e Tecnologia Ambiental (e-ISSN: 2236-1170)

Além das barreiras tarifárias, o setor citrícola enfrenta exigências fitossanitárias e técnicas dos países importadores, o que afeta a comercialização e muitas vezes encarece o fornecimento de suco de laranja. Um exemplo claro foi o caso dos Estados Unidos que barrou, no início de 2012, a entrada do suco brasileiro de laranja concentrado, cujos testes indicavam a presença de pequenas doses de Carbendazim 5 (FRANCO, 2012).

Na União Europeia, conforme Neves et al. (2010, p. 24), deve-se respeitar a legislação local e estar em conformidade com o Codex Alimentarius, conjunto de normas aceitas mundialmente acerca da produção de alimentos e da segurança alimentar. Além disso, exige-se o cumprimento da legislação do mercado exportador, que contempla as leis gerais de exportação de alimentos, as específicas para suco de frutas, presença de contaminantes, pesticidas, e exigências quanto às certificações principalmente dos orgânicos (NEVES et al., 2010, p. 24).

$\mathrm{Na}$ China as tarifas sobre importação são conforme a temperatura do suco: 7,5\% para o suco abaixo de $-18^{\circ} \mathrm{C}$ e $30 \%$ para sucos acima desta temperatura (NEVES et al., 2010, p. 24). Outra exigência, de acordo com a mesma fonte, é relativa aos níveis máximos de contaminação microbiológica: os níveis da China são 25 vezes mais rigorosos do que os da Europa, e até 50 vezes acima dos níveis aceitáveis no mercado norte-americano.

Desse modo, como o Brasil destaca-se como exportador do suco de laranja, ele precisa estar atento aos requisitos impostos pelos seus parceiros comerciais, além de perceber as exigências do consumidor nacional quanto aos seus produtos. Os importadores europeus, por exemplo, principais alvos do suco brasileiro, exigem:

[...] segurança (saúde do consumidor, níveis de contaminantes, resíduos de pesticidas), qualidade (apelo sensorial e compliance com especificações técnicas), autenticidade (adulteração, compliance com legislação), rastreabilidade (identidade do produto na cadeia de sucos de frutas, facilidade para encontrar origem de possíveis problemas), e a percepção dos consumidores (imagem do produto, origem). Quanto aos requerimentos legais, deve-se observar a legislação local, o Codex alimentarius, a legislação do mercado exportador (legislação sobre alimentos, sucos, contaminantes, aditivos, pesticidas, alergênicos, orgânicos) (NEVES et al., 2010, p. 24).

\section{ÓLEOS ESSENCIAIS CÍTRICOS}

A maior parte das exportações brasileiras de citros deve-se aos produtos oriundos do processamento industrial: o suco de laranja concentrado e congelado (FCOJ), o suco de laranja não-concentrado (NFC) e subprodutos industriais, como o óleo essencial da laranja, o d-limoneno, os terpenos cítricos e o farelo da polpa (CITRUSBR, 2011b).

De acordo com a base de dados americana United Nations Commodity Trade Statistics Database (COMTRADE, 2005 apud BIZZO et al., 2009), os maiores consumidores de óleos essenciais no mundo são os Estados Unidos (40\%) e a União Europeia (30\%), sendo a França o país líder em importações. O mercado mundial de óleos essenciais gira em torno de US\$ 15

5 O Carbendazim deixou de ser permitido nos Estados Unidos no final de 2009, apesar de ser aceito pela Organização Mundial do Comércio (OMC). O fungicida combate duas doenças muito comuns nos pomares brasileiros de citros: pinta-preta (pintas escuras na fruta que afeta principalmente o comércio da laranja de mesa) e estrelinha (fungo que ataca o pomar na fase de floração e derruba flores que iriam se transformar em frutos) (FRANCO, 2012). 


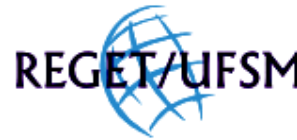

ZULIAN, DÖRR, ALMEIDA, v(11), no 11, p. 2290-2306, JUN, 2013.

Rev. Elet. em Gestão, Educação e Tecnologia Ambiental (e-ISSN: 2236-1170)

milhões/ano, apresentando crescimento aproximado de $11 \%$ ao ano (COMTRADE, 2005 apud BIZZO et al., 2009).

Segundo Bizzo et al. (2009), o Brasil destaca-se na produção de óleos essenciais, ao lado da Índia, China e Indonésia, que são considerados os quatro grandes produtores mundiais. Para os mesmos autores, o Brasil aparece entre os principais países fornecedores dos óleos essenciais de laranja, limão, lima e outros cítricos, contribuindo com $5 \%$ do total de óleos importados.

Apesar disso, o desempenho do comércio exterior brasileiro de exportação de óleos essenciais decresceu entre 2003 e 2005 tanto em relação ao volume quanto em relação à receita, passando de 69.521 toneladas (US\$ $1.649 .640,00$ ) para 59.745 toneladas (US\$ $1.275 .720,00$ ) (FERNANDES, 2005). Entre as principais variedades de óleos essenciais exportados pelo Brasil em 2007, destacam-se os óleos cítricos, pau-rosa, eucalipto e candeia (MATTOSO, 2007). Segundo dados do Ministério do Desenvolvimento, Indústria e Comércio Exterior (ALICEWEB, 2012), o Brasil apresentou, no ano de 2011, um volume total de exportação de mais de 24 milhões quilogramas (superior a US\$ 128 milhões).

As importações brasileiras de óleos essenciais mostraram uma tendência de crescimento nesses últimos anos. Em novembro de 2007, houve mais de US\$ 12 milhões em importação de óleos essenciais cítricos, sendo que o principal óleo importado pelo Brasil foi o de limão (MATTOSO, 2007).

\section{AGRONEGÓCIO COOPERATIVO}

Para Bialoskorski Neto (1999), há uma recente tendência no cooperativismo conhecida como Nova Geração de Cooperativas (NGC's). Ele aponta a importâncias das cooperativas para o agronegócio brasileiro em função principalmente da agregação de valor às commodities agrícolas e ao poder de barganha por parte do produtor. Mas o autor defende que as vantagens só existirão se forem modificados os direitos de propriedade presente na antiga doutrina cooperativista, permitindo maior eficiência econômica para a cooperativa. Bialoskorski Neto (2009, p. 726) descreve o que seria essa Nova Geração de Cooperativas (NGC):

[...] é definida como uma forma de arquitetura do empreendedorismo cooperativo que mantém os princípios doutrinários do cooperativismo, como a cada associado sendo destinado um único voto - igualitarismo - e a participação nos resultados, de acordo com as atividades de cada um com sua empresa - pro rata, mas que traz modificações nos direitos de propriedade, para induzir a organização cooperativa a um nível maior de eficiência econômica (BIALOSKORSKI NETO, 2009, p. 726).

Nesse caso, a visão e o objetivo inicial são os de mercado e não mais dos produtores, e cada associado deve contribuir com o capital do novo empreendimento proporcional a produção que ele entregará futuramente para a cooperativa (BIALOSKORSKI NETO, 2009, p. 726). Esse valor, segundo o mesmo autor, será a quota de participação de cada associado, permitindo que ele transacione com sua cooperativa o valor já estipulado anteriormente e com a qualidade também pré-estipulada. Bialoskorski Neto (2009, p. 127) acrescenta que os direitos de uso da planta processadora da cooperativa são transferíveis, o que garante que o investimento realizado pelo produtor seja uma reserva de valor. Ou seja, "essas organizações mantêm os princípios 
REGEIATFSM ZULIAN, DÖRR, ALMEIDA, v(11), no 11, p. 2290-2306, JUN, 2013.

Rev. Elet. em Gestão, Educação e Tecnologia Ambiental (e-ISSN: 2236-1170)

doutrinários e os objetivos da cooperação, mas, por outro lado, permitem que haja estímulo e incentivo no incremento da eficiência econômica e coordenação do sistema agroindustrial" (BIALOSKORSKI NETO, 2009, p. 727).

Segundo levantamento da Aliança Cooperativa Internacional ( $\mathrm{ACl}, 2011)$, existem aproximadamente um bilhão de membros de cooperativas em 90 países, o equivalente a $1 / 7$ da população da Terra. Ou seja, "a cada sete pessoas no mundo, uma está associada a uma cooperativa", sendo que só no Brasil, "estima-se em 30 milhões o número de pessoas envolvidas com o cooperativismo" (SESCOOP, 2012).

Em 2010, segundo a Organização das Cooperativas Brasileiras (OCB, 2010), havia 6.652 cooperativas no Brasil. Deste montante, a maior parte, $23 \%$, pertence ao ramo agropecuário, que apresentou 943.054 associados e 146.011 empregados em 2010. De acordo com a OCB (2010), $49 \%$ do total de empregos diretos gerados pelos diferentes ramos de cooperativas (crédito, trabalho, saúde, educação, transporte, etc.) foram proporcionados pelas cooperativas agropecuárias. Isso evidencia a importância da cooperativa não apenas para o produtor associado, mas também para o mercado de trabalho.

Outro importante levantamento realizado pela OCB demonstrou um aumento considerável nos produtos exportados oriundos das cooperativas agropecuárias: de 2000 a 2010 as exportações desses produtos aumentaram 582\%, obtendo um total de US\$ 4,4 bilhões em exportações diretas (OCB, 2010). Os principais grupos desses produtos são: $39,3 \%$ do complexo sucroalcooleiro, $25,6 \%$ do complexo soja e $16,9 \%$ do setor de carnes. Além destes, $9,2 \%$ referem-se ao grupo do café, chá e especiarias, $2,2 \%$ dos cereais, $1,7 \%$ do algodão, $0,9 \%$ das frutas, $0,8 \%$ dos produtos hortículas e suas preparações e, por fim, $0,7 \%$ do grupo do leite e laticínios (OCB, 2010).

A importância do cooperativismo é percebida também na recente decisão da Organização das Nações Unidas (ONU) "que definiu o ano de 2012 como o Ano Internacional das Cooperativas, colocando o cooperativismo em evidência no mundo" (SESCOOP, 2012). A frase dita pelo Secretário Geral da ONU, Ban Ki-moon, justifica essa decisão: "As cooperativas demonstram para a comunidade internacional que é possível perseguir tanto a viabilidade econômica quanto a responsabilidade social" (SESCOOP, 2012).

Gimenes e Gimenes (2006) abordaram a importância do cooperativismo agropecuário na cadeia de valor do agronegócio nacional. Eles concluem que o principal desafio das sociedades cooperativas é a de manter-se como uma empresa competitiva, capaz de enfrentar multinacionais de grande porte e, ao mesmo tempo, atender às necessidades dos seus associados. $E$ isso impõe limites à expansão das cooperativas com recursos próprios (autofinanciamento), que são limitados e necessitam de recursos financeiros de terceiros.

Além de incentivar a criação de cooperativas agropecuárias, é importante a prática da gestão, uma vez que a entidade envolve um grande grupo de pessoas e se relaciona com o mercado competitivo. Ferreira (2009) afirma que o sistema cooperativo funciona como uma solução para os pequenos e médios produtores. Esse sistema é baseado na autogestão, e faz com que as cooperativas adotem estratégias de gestão adequadas e eficientes. $O$ autor cita ferramentas administrativas e contábeis de gestão e evidencia a importância destas no processo decisório na cadeia do agronegócio cooperativo.

Jerônimo et al. (2006) também abordam o tema da gestão nas sociedades cooperativas, com foco em uma cooperativa agropecuária gaúcha. $\mathrm{O}$ estudo de caso objetivou identificar e analisar a gestão estratégica de uma cooperativa agropecuária do setor alimentar, localizada no 
REGETAUFSM ZULIAN, DÖRR, ALMEIDA, v(11), no 11, p. 2290-2306, JUN, 2013.

Rev. Elet. em Gestão, Educação e Tecnologia Ambiental (e-ISSN: 2236-1170)

Vale do Taquari, região noroeste do estado do Rio Grande do Sul. O estudo concluiu que os principais entraves de gestão estratégica em cooperativas estão associados à limitação de recursos, à cultura e à deficiência na tomada de decisão. Por outro lado, segundo o mesmo trabalho, as cooperativas agropecuárias demonstram contar com pontos fortes, por terem acesso à produção agropecuária, e contarem com a possibilidade de coordenar a produção.

Uma estratégia de organização no agronegócio é a integração vertical. Esta é constituída de um conjunto de atividades que compõem o agronegócio de um ou mais produtos, incluindo os setores "antes, durante e após a porteira", tendo como gestora uma empresa (cooperativa, sociedade anônima, condomínios) que coordena as atividades (ARAÚJO, 2003 apud SILVA, 2006, p. 14). Ou seja, para a adoção da estratégia de integração vertical, a firma deve participar de vários estágios: desde o preparo da matéria-prima até a comercialização do produto final (SILVA, 2006, p. 35). Conforme Silva (2006, p. 16), "a integração vertical leva à garantia de fornecimento, à redução de custos por parte das empresas integradas, e, por fim, à redução dos preços finais para o consumidor".

Belusso (2007) analisa a implantação de agroindústrias por cooperativas agrícolas do Paraná, de modo a romper com o processo de apenas receber e comercializar matérias-primas entregues pelos sócios. Segundo a autora, atualmente, os produtores precisam estar engajados com os novos interesses dos consumidores e padrões de produção, buscando capacitação, acesso a novas tecnologias e conseguindo, assim, atuar no mercado competitivo. Dessa forma, Belusso (2007) conclui que existe diferença entre a teoria das cooperativas e a prática, sendo que as cooperativas buscam cumprir funções de empresa representante dos seus sócios.

Seguindo esta linha, Schubert e Niederle (2009) demonstraram a importância do cooperativismo para pequenos produtores rurais do setor leiteiro de Santa Catarina. Este é um mercado caracterizado pela oligopolização, onde a atuação de líderes tem exigido inovações tecnológicas, organizacionais e informacionais para conseguir competir no mercado (SCHUBERT e NIEDERLE, 2009). Isso representa desafios ao agricultor familiar, mas apesar de um contexto adverso em termos de mercado, eles têm encontrado meios para lidar com esses desafios econômicos, isso se verifica pela quantidade de cooperativas existentes (SCHUBERT e NIEDERLE, 2009).

O agronegócio cooperativo ganha destaque na diferenciação de produtos. Conforme Maluf (2004, p. 320), os projetos de agregação de valor enfrentam as exigências próprias da participação no mercado formal de alimentos. O consumidor está exigindo novos padrões de alimentação, sendo que a valorização de produtos com atributos diferenciados de qualidade cria novas oportunidades de mercado que, muitas vezes, se tornam acessíveis aos agricultores de pequeno e médio portes (MALUF, 2004). Conforme Maluf (2004), essas novas oportunidades abrangem o acesso desses agricultores em mercados nacionais e internacionais, como é o caso da produção de orgânicos.

\section{CONCLUSÕES}

Apesar de não ser o foco econômico e produtivo da maioria dos estados brasileiros, a citricultura desenvolve um papel importante na balança comercial brasileira, no crescimento e no desenvolvimento econômico de várias regiões. Além da comercialização da fruta cítrica, essa 


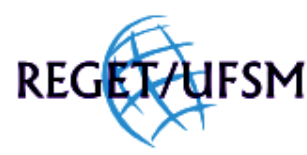

ZULIAN, DÖRR, ALMEIDA, v(11), no 11, p. 2290-2306, JUN, 2013.

Rev. Elet. em Gestão, Educação e Tecnologia Ambiental (e-ISSN: 2236-1170)

atividade compreende a agroindustrialização, com destaque para a produção do suco e do óleo essencial.

A realização do processamento da fruta cítrica e na transformação em suco ou óleo essencial exige aprimoramento da atividade e adoção de técnicas diferenciadas. Esse tipo de atividade é muitas vezes dificultada na figura de um pequeno produtor. Com isso, surge a importância do agronegócio cooperativo, que reúne produtores e permite a diferenciação da produção juntamente com a agregação de valor.

O papel do cooperativismo no agronegócio brasileiro representa uma forma de incluir os pequenos produtores em técnicas diferenciadas e que, muitas vezes, são dificultadas na atuação individual. Uma associação ou cooperativa possibilita a inserção do pequeno produtor no mercado competitivo e, através da parceria com órgão de pesquisa, promove o crescimento do setor e a diferenciação deste, agregando valor à matéria-prima oriunda do meio rural. Além disso, através de uma cooperativa, é possível determinar a viabilidade econômica da produção agrícola, pois o controle dos custos é realizado e é feita a estimativa de lucros ou prejuízos. Este é um fator determinante no sucesso em qualquer ramo da atividade econômica, mas ainda é pouco encontrado na realidade da pequena produção agropecuária brasileira. Assim, a viabilização da propriedade rural está na qualidade gerencial, ou seja, na boa administração e condução das atividades.

Por fim, o investimento em pesquisa e desenvolvimento é muitas vezes dificultado para a figura de um pequeno produtor, que tem limitações no acesso a informações e de assistência técnica. No entanto, através da união formal dos produtores na figura de uma associação ou cooperativa, com a divisão de tarefas e o planejamento, o acesso a inovação, ao conhecimento e a diferenciação da produção são fatores possíveis de serem alcançados.

\section{REFERÊNCIAS BIBLIOGRÁFICAS}

ACl. Aliança Cooperativa Internacional. Portal do Cooperativismo de Crédito. 2011. Disponível em: <http://www.cooperativismodecredito.com.br/ACI.html>. Acesso em: 10 dez. 2012.

ALICEWEB. Estatísticas. Ministério do Desenvolvimento, Indústria e Comércio Exterior. 2012. Disponível em: <http://aliceweb.desenvolvimento.gov.br/>. Acesso em: 24 fev. 2012.

BELUSSO, D. A cooperativa C. Vale e as perspectivas dos produtores integrados à agroindústria em Palotina - PR. 2007. 100 f. Dissertação (Mestrado em Geografia) - Universidade Estadual do Maringá, Maringá - PR, 2007. Disponível em: <http://www.pge.uem.br/pdf/dbelusso.pdf>. Acesso em: 12 dez. 2012.

BIALOSKORSKI NETO, S. Agronegócio cooperativo. In: BATALHA, M. O. (Coord.). Gestão agroindustrial. São Paulo: Atlas, 2009.

BIALOSKORSKI NETO, S. A nova geração de cooperativas e a coordenação de sistemas agroindustriais. In: Workshop Brasileiro de Gestão de Sistemas Agroalimentares, 2., Ribeirão Preto, p. 164-171, 1999. Ribeirão Preto:

PENSA/FEA/USP, 1999. Disponível em: <http://www.fearp.usp.br/egna/arquivo/15.pdf>. Acesso em: 11 mar. 2012.

BIZZO, H. R.; HOVELL, A. M. C.; REZENDE, C. M. Óleos essenciais no Brasil: aspectos gerais, desenvolvimento e perspectivas. Química Nova, São Paulo, v. 32, n. 3, p. 588-594, 2009. Disponível em: <http://www.scielo.br/pdf/qn/v32n3/a05v32n3.pdf>. Acesso em: 11 mar. 2012. 


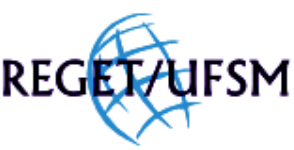

ZULIAN, DÖRR, ALMEIDA, v(11), no 11, p. 2290-2306, JUN, 2013.

Rev. Elet. em Gestão, Educação e Tecnologia Ambiental (e-ISSN: 2236-1170)

CITRUSBR. Produção de Laranja e Suco. Associação Nacional dos Exportadores de Sucos Cítricos, São Paulo, 2011a. Disponível em: <http://www.citrusbr.com/exportadorescitricos/setor/producao-192415-1.asp>. Acesso em: 10 mar. 2012.

CITRUSBR. Exportações Brasileiras do Complexo Citrícola. Associação Nacional dos Exportadores de Sucos Cítricos, São Paulo, 2011b. Disponível em: <http://www.citrusbr.com/exportadores-citricos/setor/exportacoes-brasileiras-docomplexo-citricola-193132-1.asp>. Acesso em: 10 mar. 2012.

DONADIO, L. C.; STUCHI, E. S.; CYRILLO, F. L. de L. Tangerinas ou mandarinas. Boletim Citrícola, Jaboticabal: Funep, n. 5, p. 01- 40, 1998.

FAOSTAT. Food and Agriculture Organization of the United Nations. Statistics. 2012. Disponível em: <http://faostat.fao.org/>. Acesso em: 24 fev. 2012.

FAOSTAT. Food and Agriculture Organization of the United Nations. Statistics. 2011. Disponível em: <http://faostat.fao.org/>. Acesso em: 24 fev. 2012.

FERNANDES, I. F. O desempenho do Comércio Exterior Brasileiro de óleos Essenciais. In: Simpósio Brasileiro de Óleos Essenciais, 3, 2005, Campinas. Campinas: IAC, 2005.

FERREIRA, J. M. Gestão do agronegócio cooperativo. Revista do Núcleo Interdisciplinar de Pesquisa e Extensão do UNIPAM, Patos de Minas: UNIPAM, v. 6, p. 163-172, 2009. Disponível

em:<http://www.unipam.edu.br/perquirere/file/file/2009/gestao_do_agronegocio_cooperativo.pdf>. Acesso em: 10 mar. 2012.

FRANCO, L. Citricultor pode suspender o uso de fungicidas não aprovados nos EUA. Globo Rural, 06 fev., 2012. Disponível em: <http://revistagloborural.globo.com/Revista/Common/0,,EMI293290-18078,00-

CITRICULTOR+PODE+SUSPENDER+O+USO+DE+FUNGICIDAS+NAO+APROVADOS+NOS+EUA.html>. Acesso em: 02 mar. 2012.

GIMENES, R. M. T.; GIMENES, F. M. P. Agronegócio cooperativo: a transição e os desafios da competitividade, Revista Ciências Empresariais da UNIPAR, Umuarama, v. 7, n. 1, p. 33-46, 2006.

JERÔNIMO, F. B.; MARASCHIN, A. de F.; SILVA, T. N. da. A gestão estratégica de sociedades cooperativas no cenário concorrencial do agronegócio brasileiro: estudo de caso em uma cooperativa agropecuária gaúcha. Teoria e Evidência Econômica, Passo Fundo, v. 14, n. 26, p. 71-90, 2006.

MALUF, R. S. Mercados agroalimentares e a agricultura familiar no Brasil: agregação de valor, cadeias integradas e circuitos regionais. Ensaios FEE, Porto Alegre, v. 25, n. 1, p. 299-322, 2004.

MATTOSO, E. O Mercado interno de óleos essenciais: desafios e oportunidades. In: Simpósio Brasileiro de Óleos Essenciais, 4., Fortaleza- CE, 2007.

MILOCA, L. M.; SAURIN, G.; STADUTO, J. A. R. O Processo de Coordenação de Cadeias Agroalimentares: Uma análise da Cadeia Produtiva da Mandioca no Paraná. Associação Brasileira dos Produtores de Amido de Mandioca, 2005. Disponível em: <http://www.abam.com.br/mat_tecnicos.php>. Acesso em: 15 mar. 2012.

NEVES, M. F. Sistema agroindustrial citrícola: um exemplo de quase-integração no agribusiness brasileiro. $1995.83 \mathrm{f}$. Dissertação (Mestrado em Admnistração de Empresas) - Faculdade de Economia, Administração e Contabilidade (F.E.A.) da Universidade de São Paulo, São Paulo, 1995. Disponível em:

<http://www.fearp.usp.br/fava/pdf/DissertacaoMestrado.pdf>. Acesso em: 15 abr. 2012. 


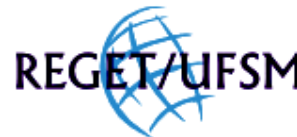

ZULIAN, DÖRR, ALMEIDA, v(11), no 11, p. 2290-2306, JUN, 2013.

Rev. Elet. em Gestão, Educação e Tecnologia Ambiental (e-ISSN: 2236-1170)

NEVES, M. F. et al. O Retrato da Citricultura Brasileira. In: NEVES, M. F. (Coord.). 1. ed. Ribeirão Preto: Markestrat, 2010. 138 p. Disponível em: <http://www.favaneves.org/arquivos/retrato-citricultura-brasileira-marcos-fava.pdf>. Acesso em: 10 mar. 2012.

NEVES, M. F.; JANK, M. S. Perspectivas da cadeia produtiva da laranja no Brasil: a agenda 2015. Relatório Ícone/Markestra/Pensa, São Paulo, 2006. Disponível em:

<http://www.fundace.org.br/arquivos_diversos/agenda_estrategica/Agenda_Citrus_2015_PENSAICONE.pdf >. Acesso em: 15 abr. 2012.

NEVES, M. F.; MARINO, M. K. Estudo da competitividade de cadeias integradas no Brasil: impactos das zonas de livre comércio. Nota Técnica Final, Campinas: UNICAMP, 2002. 74 p. Disponível em:

<http://rO.unctad.org/infocomm/francais/orange/Doc/competitivite.pdf>. Acesso em: 20 mar. 2012.

OCB. Apresentação Institucional Sistema Cooperativista. Organização das Cooperativas Brasileiras, 2011. Disponível em:

<http://www.brasilcooperativo.coop.br/GERENCIADOR/ba/arquivos/140411_apresentacaoinstitucional2010_1.pdf>. Acesso em: 15 mai. 2012.

RAPPA, C. (Ed.). Busca da qualidade é destaque no VII Dia da Tangerina. Informativo centro de citricultura, Cordeirópolis, n. 108, 2004.

SCHUBERT, M. N.; NIEDERLE, P. A. Estratégias competitivas do cooperativismo na cadeia produtiva do leite: o caso da Ascooper, SC. In: Congresso da sociedade brasileira de economia, administração e sociologia rural, 47., 2009, Porto Alegre. Anais... Porto Alegre, 2009. Disponível em: <http://www.sober.org.br/palestra/13/104.pdf>. Acesso em: 15 abr. 2012.

SESCOOP. Serviço Nacional de Aprendizagem do Cooperativismo. Relatório de Gestão do Exercício de 2011. Brasília, 2011. Disponível em: <http://www.brasilcooperativo.coop.br/site/transparenciasescoop/gestaoun/UN-2011.pdf>. Acesso em: 12 dez. 2012.

SILVA, L. C. da. Integração vertical contratual no agronegócio: um estudo no complexo agroindustrial da mandioca em Deodápolis, MS. 2006. 119 f. Dissertação (Programa de Pós-Graduação em Engenharia de Produção) - Faculdade de Engenharia Mecânica e de Produção da Universidade Metodista de Piracicaba (UNIMEP), Santa Bárbara d'Oeste, 2006. 